\title{
Impacto econômico das políticas e ações públicas relacionadas aos distúrbios do sono no Brasil
}

Beny Jose FINKELSTEIN: Faculdade de Saúde Pública - FSP, Universidade de São Paulo - USP. ORCID: https://orcid.org/0000-0003-4191-6907

Lúcia Dias da Silva GUERRA: Centro Universitário Anhanguera/campus Santana; Faculdade de Saúde Pública - FSP, Universidade de São Paulo - USP. ORCID: https://orcid.org/0000-0003-00932687

Recebido: 5 out. 2020

Aceito: 21 out. 2020

Autor de correspondência: Beny Finkelstein

benyfink@gmail.com

Conflito de interesses: Os autores declaram não haver nenhum interesse profissional ou pessoal que possa gerar conflito de interesses em relação a este manuscrito.

\section{Resumo}

Desde a criação da medicina social e extremamente interligado a evolução dos processos de produção no século XVIII, políticas públicas com foco na saúde do trabalhador visam não somente acesso destes aos direitos fundamentais de cada país, mas também impactos econômicos para a sociedade. O pensamento econômico em saúde e a economia política visam guiar o processo de consolidação de decisões em saúde que culminam em políticas sociais de gestão para serem aplicados na sociedade através da regulação. No Brasil, a saúde é um direito fundamental e faz parte da Constituição Federal (1988), onde através do Art. 196 especifica-se como um direito de todos e um dever do estado, garantido mediante a políticas sociais e econômicas. Estas políticas sociais de atenção em saúde estão organizadas em gestão de serviços, e estes divididos em ações de promoção, proteção e recuperação. Estas organizações devem estar constituídas em redes de atenção à saúde e que são organizações poliárquicas de conjuntos de serviços em saúde, vinculados entre si por objetivos comuns e por uma ação cooperativa e interdependente que permitem ofertar uma ação contínua e integral. Segundo a matriz conceitual da Portaria do Ministério da Saúde GM 4.279/2010 estas redes devem estar organizadas para a atenção a saúde da tripla carga de doenças, subdivididas em condições agudas e condições crônicas através de serviços de atenção primária e serviços secundários e terciários, a depender da complexidade, por dentro de cuidado multiprofissional e compartilhando objetivos e compromissos com resultados sanitários e econômicos. A gestão de serviços em saúde possui redes temáticas para o gerenciamento de problemas similares afim de otimizar o resultado. Uma destas redes temáticas, regulamentadas através da Portaria № 483/2014 5 é a de atenção a pessoas com doenças crônicas. Os distúrbios do sono são um conjunto de doenças crônicas e agudas que podem ser agrupados em dois grandes grupos, sendo eles as dissônias e as parassônias. A ligação da apneia do sono com outras doenças crônicas é amplamente documentada, estima-se que parte dos pacientes possam ter AVC, hipertensão residente coroniopatias, obesidade e diabetes, mas tem boa diminuição de riscos agravados destas condições se tratados adequadamente. $O$ estudo foi realizado através de uma revisão integrativa de literatura, dividida em três etapas: planejamento e pré-teste, identificação, seleção e extração dos dados. As bases de dados utilizadas foram BVS/Lilacs, Scielo, Pubmed/Medline, Scopus, Web of Science, Embase, Cinahl, todas devido a sua extensa bibliografia relacionada a artigos científicos, econômicos e de saúde pública. Os termos de busca foram categorizados em Objeto, Fenômeno e Contexto, sendo: Distúrbios do sono (OBJETO), Impacto Econômico (FENÔMENO) e Políticas Públicas (CONTEXTO). Foram incluidos artigos cientificos em português, inglês e espanhol e foram excluidos todos os artigos que não estivessem na perspectiva brasileira. Para a base de dados BVS/LILACS a estratégia de busca foi de realizar a sintaxe conjunta de Doenças do 
sono, Políticas Públicas e Economia da Saúde de forma conjunta, em cada um dos idiomas de busca (português, inglês e espanhol). Para estas buscas foram encontrados 183 artigos em português, 391 em inglês e 192 em espanhol, totalizando um total de 766 artigos. Para a base de dados SCIELO a estratégia de busca foi de realizar a sintaxe conjunta de Doenças do sono, Políticas Públicas e Economia da Saúde de forma conjunta apenas em português. Para esta busca foram encontrados dois artigos. Para a base de dados PubMed/Medline a estratégia de busca foi de realizar a sintaxe conjunta de Doenças do sono, Políticas Públicas e Economia da Saúde de forma conjunta apenas em inglês, totalizando ao total de todas as bases dados, idiomas e estratégias foram exportados 775 artigos, dos quais 382 estiveram repetidos e restando 383 para análise posterior de título e resumo. Para retirada de artigos duplicados utilizou-se o gerenciador Zotero, em seguida foi gerada uma planilha em Excel com as principais informações dos artigos. Espera-se com esta revisão identificar estudos sobre as políticas públicas ou ações de saúde relacionadas as doenças do sono no Brasil e discutir os seus efeitos econômicos para o Estado e a sociedade, tomando como ponto de partida a importância da saúde do trabalhador.

Descritores: Transtornos do Sono-Vigília; Política Pública; Economia da Saúde.

Keywords: Sleep Wake Disorders; Public Policy; Health Economics.

Palabras-claves: Trastornos del Sueño-Vigilia; Politica Pública; Economía de la Salud. 